\title{
Factors contributing to the time taken to consult with symptoms of lung cancer: a cross-sectional study
}

\author{
S M Smith, ${ }^{1}$ N C Campbell, ${ }^{1}$ U MacLeod, ${ }^{2}$ A J Lee, ${ }^{1}$ A Raja, ${ }^{3}$ S Wyke, ${ }^{4}$ S B Ziebland, ${ }^{5}$ \\ E M Duff, ${ }^{2}$ L D Ritchie, ${ }^{1}$ M C Nicolson ${ }^{6}$
}

${ }^{1}$ Centre of Academic Primary Care, University of Aberdeen, Aberdeen, UK; ${ }^{2}$ Department of General Practice and Primary Care, University of Glasgow, Glasgow, UK; ${ }^{3}$ Department of Public Health, University of Aberdeen, Aberdeen, UK;

${ }^{4}$ Department of Nursing and Midwifery, University of Stirling, Stirling, UK; ${ }^{5}$ Department of Primary Health Care, University of Oxford, Oxford, UK;

${ }^{6}$ Aberdeen Royal Infirmary, NHS Grampian, Aberdeen, UK

Correspondence to: Ms S M Smith, Centre of Academic Primary Care, University of Aberdeen, Foresterhill Health Centre, Westburn Road, Aberdeen AB25 2AY, UK; s.m.smith@abdn.ac.uk

Received 30 January 2008 Accepted 6 November 2008 Published Online First

2 December 2008

\begin{abstract}
Objectives: To determine what factors are associated with the time people take to consult with symptoms of lung cancer, with a focus on those from rural and socially deprived areas.
\end{abstract}

Methods: A cross-sectional quantitative interview survey was performed of 360 patients with newly diagnosed primary lung cancer in three Scottish hospitals (two in Glasgow, one in NE Scotland). Supplementary data were obtained from medical case notes. The main outcome measures were the number of days from (1) the date participant defined first symptom until date of presentation to a medical practitioner; and (2) the date of earliest symptom from a symptom checklist (derived from clinical guidelines) until date of presentation to a medical practitioner

Results: 179 participants (50\%) had symptoms for more than 14 weeks before presenting to a medical practitioner (median 99 days; interquartile range 31-381). 270 participants $(75 \%)$ had unrecognised symptoms of lung cancer. There were no significant differences in time taken to consult with symptoms of lung cancer between rural and/or deprived participants compared with urban and/or affluent participants. Factors independently associated with increased time before consulting about symptoms were living alone, a history of chronic obstructive pulmonary disease (COPD) and longer pack years of smoking. Haemoptysis, new onset of shortness of breath, cough and loss of appetite were significantly associated with earlier consulting, as were a history of chest infection and renal failure.

Conclusion: For many people with lung cancer, regardless of location and socioeconomic status, the time between symptom onset and consultation was long enough to plausibly affect prognosis. Long-term smokers, those with COPD and/or those living alone are at particular risk of taking longer to consult with symptoms of lung cancer and practitioners should be alert to this.

Only $7 \%$ of patients with lung cancer in Scotland are alive 5 years after diagnosis; ${ }^{1}$ a similar picture exists in England and Wales. ${ }^{2}$ Five-year lung cancer survival rates in the UK are well below the average rates of Europe and America. ${ }^{2}$ So too are surgical resection rates; only $11 \%$ of patients in the UK receive curative surgery compared with $17 \%$ in Europe and $21 \%$ in North America. ${ }^{1}$ Differences in collection and presentation of data may account for some of this variation, but the "consistency of international comparisons" suggests that other factors are also at play. ${ }^{3}$ Stage at diagnosis is one such factor. Most patients with lung cancer in the UK are diagnosed at a late stage when curative surgery is no longer an option. ${ }^{45}$ Late presentation of symptoms to a medical practitioner is recognised as being part of the problem. ${ }^{4-8}$

Late presentation of cancer symptoms is a common and well-documented event. ${ }^{8-11}$ Decisions on when to seek medical help are often bound up in a complex mix of individual psychosocial factors. ${ }^{12-14}$ The effects of previous public and professional neglect of lung cancer may also still endure. A recent qualitative study reported late presentation of lung cancer symptoms as a universal feature. ${ }^{8}$ Participants, regardless of their disease stage, failed to recognise the seriousness of their symptoms and reported noticeable changes in health long before seeking medical help. This and other lung cancer research ${ }^{15}$ challenges the general belief that lung cancer is asymptomatic until advanced.

Geographical variation in lung cancer survival also exists within the UK. Research into cancer inequalities in Scotland has shown that people from rural and deprived areas have poorer lung cancer survival than people from urban and affluent areas. ${ }^{16-19}$ There is no evidence that healthcare providers in Scotland differentially delay referral and/or treatment for lung and other cancers in these groups. ${ }^{20-22}$ Differences in attitude to consulting a clinician with symptoms of cancer between people in rural and urban areas have been reported, ${ }^{23}$ but whether those in rural and deprived communities wait longer before seeking medical help is unknown. A delay of even a few months in seeking medical help is believed to have a significant influence on stage at diagnosis and prognosis. ${ }^{24}$ Reducing the time taken to consult with symptoms of lung cancer in those more likely to postpone seeking medical help may help improve survival. ${ }^{25}$ However, as the reasons for late presentation are not fully understood, a greater appreciation of the process that occurs before first contact with a medical practitioner is required. This study aimed to explore this process and to determine what patient factors are associated with the time taken to consult with symptoms of lung cancer, and whether those from rural and/or deprived areas wait longer than those from urban and/or affluent areas before seeking medical help.

\section{METHODS}

Consecutive patients with primary lung cancer were identified by specialist nurses at three Scottish hospitals (one in north-east Scotland and two in Glasgow) early after diagnosis between April 2004 and January 2006. Both locations treat patients across the spectrum of rurality and deprivation. 
Table 1 Participant demographic and socioeconomic characteristics $(n=360)$

\begin{tabular}{|c|c|}
\hline Characteristic & No (\%) \\
\hline \multicolumn{2}{|l|}{ Age group (years) } \\
\hline$\leqslant 49$ & $18(5)$ \\
\hline $50-59$ & $74(21)$ \\
\hline $60-69$ & $114(32)$ \\
\hline $70-79$ & $122(34)$ \\
\hline$\geqslant 80$ & $32(9)$ \\
\hline \multicolumn{2}{|l|}{ Sex } \\
\hline Male & $210(58)$ \\
\hline Female & $150(42)$ \\
\hline \multicolumn{2}{|l|}{ Ethnicity } \\
\hline White & $359(>99)$ \\
\hline Pakistani & $1(<1)$ \\
\hline \multicolumn{2}{|l|}{ Education } \\
\hline No qualifications & $153(43)$ \\
\hline Higher/A level & $110(31)$ \\
\hline $\mathrm{HNC} / \mathrm{HND}$ & $10(3)$ \\
\hline Professional/technical qualifications & $54(15)$ \\
\hline University degree & $15(4)$ \\
\hline GSVQ/SVQ & $18(5)$ \\
\hline \multicolumn{2}{|l|}{ Smoking } \\
\hline Ex-smoker & $235(65)$ \\
\hline Smoker at time of interview & $110(31)$ \\
\hline Never smoker & $15(4)$ \\
\hline \multicolumn{2}{|l|}{ Area } \\
\hline North-east Scotland & $190(53)$ \\
\hline Glasgow & $170(47)$ \\
\hline \multicolumn{2}{|l|}{ Home ownership } \\
\hline Own home & $218(60)$ \\
\hline Rent home & $132(37)$ \\
\hline Other & $10(3)$ \\
\hline \multicolumn{2}{|c|}{ Travelling distance to nearest cancer centre (miles) } \\
\hline$<5$ & $187(52)$ \\
\hline $5-<10$ & $51(14)$ \\
\hline $10-<15$ & $14(4)$ \\
\hline $15-<20$ & $17(5)$ \\
\hline $20-<25$ & $5(1)$ \\
\hline $25-<30$ & $9(3)$ \\
\hline$\geqslant 30$ & $77(21)$ \\
\hline \multicolumn{2}{|l|}{ Travelling distance to GP (miles) } \\
\hline$\leqslant 1$ & $120(33)$ \\
\hline $1-<3$ & $163(45)$ \\
\hline $3-<5$ & $56(15)$ \\
\hline $5-<7$ & $11(4)$ \\
\hline $7-<11$ & $10(3)$ \\
\hline
\end{tabular}

Indicators of deprivation were assigned to cases according to their postcode at the time of diagnosis. Carstairs deprivation scores were calculated from 2001 census data ${ }^{26}$ at the output area level (the lowest level geography used to produce statistical output from the census) and grouped into population quintiles. Rural and urban status was allocated according to quintiles of travelling distance from a participant's postcode to the nearest cancer centre; this measure was previously found to be associated with diagnosis of lung cancer at a later stage and poorer early survival. ${ }^{16}{ }^{18}$ Because of difficulties in answering survey questions, patients who had impaired consciousness, dementia or psychosis were excluded from the study. Patients considered by clinicians to be too unwell to be approached were also excluded. Participants agreeable to the study received an information sheet and allowed their details to be passed to the study researcher. Contact was made and the study was explained in full before obtaining signed consent. Data were then collected using a quantitative interview survey (see below). In addition, dates of consultations, referral and first hospital contact, and data on co-morbidities (previous cancer, chest and cardiovascular disease, gastrointestinal and hepatic disease, musculoskeletal problems and psychiatric problems) were abstracted from GP and hospital case notes.

\section{Quantitative interview survey}

Participants were asked about their initial symptoms and the dates they were first noticed. Two definitions of first symptom were used-participant-defined and health professionaldefined-using a checklist of symptoms compiled from Cancer Research UK lung cancer symptoms ${ }^{27}$ and SIGN guidelines. ${ }^{1}$ Further data included knowledge of lung cancer symptoms; previous consulting behaviour; exposure to risk factors; family history of cancer; and perception of self-risk of cancer. Individual socioeconomic data (including education, employment and home ownership) were collected to test deprivation validity at the individual patient level. Additional variables shown to be associated with illness behaviour such as living alone, having someone with whom to discuss symptoms and relationship with their GP were also included.

\section{Outcome measures}

The main outcomes were (1) the number of days from date of first symptom defined by the participant until date of presentation of symptoms to a medical practitioner and (2) the number of days from date of earliest symptom from the symptom checklist until date of presentation of symptoms to a medical practitioner.

\section{Study power}

A total sample size of 400 was projected to give $80 \%$ power to detect an absolute difference of $14 \%$ (50\% versus $36 \%$ ) in two equal group comparisons of patients waiting $>12$ weeks before presenting to a medical practitioner at the $5 \%$ significance level. If numbers in one group fell to 150 , the study would have a similar power to detect a difference of $16 \%$.

\section{Statistical analysis}

Statistical analyses were conducted using SPSS for Windows Version 15. Univariate analyses $\left(\chi^{2}\right.$ tests, Pearson correlation and $t$ tests) were performed to examine the association of the independent variables with each outcome variable. Time to consultation had a skewed distribution and a log transformation was required before analysis. The results were converted back to geometric means (transformed $95 \%$ confidence intervals, CI) for presentation of the univariate results. To determine which participant factors had an independent association with each outcome, multiple linear regression analyses were performed. The factors age, sex, distance to cancer centre, Carstairs deprivation scores and area (north-east Scotland or Glasgow) were initially forced into the model. Other factors were entered into the initial model if they had shown a significant univariate association at $p \leqslant 0.20$. A backward stepwise removal process selected predictor variables if $p>0.10$. In order to make the interpretation of the regression models easier, the antilog of each regression coefficient and its $95 \% \mathrm{CI}$ are presented. For categorical factors the resultant values can be interpreted as the number of times longer that a particular group took to consult their GP compared with the reference group. For continuous 
Table 2 Earliest checklist symptoms experienced, participant-defined first symptoms and checklist symptoms at time of presentation to a medical practitioner $(n=360)$

\begin{tabular}{llll}
\hline & $\begin{array}{l}\text { Earliest checklist } \\
\text { symptom(s) experienced } \\
\text { No (\%) }\end{array}$ & $\begin{array}{l}\text { Participant-defined } \\
\text { first symptom(s) } \\
\text { No (\%) }\end{array}$ & $\begin{array}{l}\text { Checklist symptom(s) } \\
\text { at time of } \\
\text { presentation } \\
\text { No (\%) }\end{array}$ \\
Symptoms & $70(19)$ & $117(32)$ & $218(61)$ \\
\hline Cough & $76(21)$ & $81(22)$ & $211(59)$ \\
Shortness of breath & $49(14)$ & $27(7)$ & $177(49)$ \\
Coughing up phlegm & $57(16)$ & $51(14)$ & $118(33)$ \\
Tiredness/fatigue/lethargy & $41(11)$ & $11(3)$ & $126(35)$ \\
More short of breath than usual & $71(20)$ & $27(7)$ & $124(34)$ \\
Loss of weight & $57(16)$ & $23(6)$ & $111(31)$ \\
Loss of appetite & $49(14)$ & $53(15)$ & $108(30)$ \\
Pain in chest/shoulders/back related to & & $8(2)$ & $81(22)$ \\
breathing or coughing & $38(10)$ & $3(1)$ & $68(19)$ \\
Hoarse voice & $18(5)$ & $44(12)$ & $61(17)$ \\
Change in a cough & $17(5)$ & $5(1)$ & $23(6)$ \\
Haemoptysis & $12(3)$ & $11(3)$ & $21(6)$ \\
Difficulty swallowing & $11(3)$ & $27(7)$ & $4(1)$ \\
Swelling of the face or neck & - & $2(1-2)$ & $4(2-5)$ \\
“No symptoms" (eg, incidental finding) & & & \\
\hline Median (IQR) number of symptoms experienced & $1(1-2)$ & &
\end{tabular}

factors the coefficients refer to the proportionate change in time taken to consult for each unit increase in the continuous factor.

\section{RESULTS}

Over the 92-week study period, 835 people with primary lung cancer were identified; 154 people were ineligible, most of whom were deemed too ill by clinicians to be approached about the study. A further 23 whose eligibility status was not confirmed had also to be excluded. A total of 658 were eligible for the study and 620 were approached; 113 of these refused. Of the remaining 507, 96 withdrew before giving full consent, 24 died before an interview could take place and contact was lost with 26. A total of 361 participants were recruited and completed quantitative interview surveys (all were face-to-face apart from two which were conducted by telephone). One participant reported first presenting with symptoms of lung cancer 10 years previously and was excluded from the rest of the analyses as an outlier. Three hundred and forty-six (96\%) of both hospital and GP case notes were reviewed. Comparing dates of first consultation reported by participants with GP case note recorded dates, 32\% $(n=102)$ were within 1 week, $36 \%$ $(n=114)$ between 8 and 30 days and $32 \%(n=100)$ more than 1 month. No evidence of reporting bias between affluent, deprived, rural and urban groups was found.

\section{Participant characteristics}

The sample $(n=360)$ consisted of $58 \%$ men and $42 \%$ women. The characteristics of the participants are shown in table 1 . Their median age was 68 years (interquartile range (IOR) 59-74), ranging from 37 to 87 years. Sixty-two (17\%) lived in the least deprived areas (Carstairs quintile 1) and 128 (36\%) lived in the most deprived areas (Carstairs quintile 5). The median travelling distance to a cancer centre was 4.5 miles (IOR 2.2-22.0), range 0.6-227 miles, and 77 (21\%) lived 30 miles or more from their nearest cancer centre. Three hundred and thirty-five (78\%) lived within 3 miles of their GP. Only $4 \%$ of the participants had never smoked and 201 (56\%) of smokers and ex-smokers reported not perceiving themselves to be at risk of lung cancer before their diagnosis despite being aware of the risks of smoking. Two hundred and seventy $(75 \%)$ reported having no knowledge of lung cancer symptoms and 171 (51\%) reported not having believed that their first symptom(s) was serious.

\section{Time to presentation of symptoms}

The median time from participant-defined first symptoms to consultation with a medical practitioner was 21 days (IOR 7-56). The median time from earliest reported checklist symptoms until consultation was 99 days (IOR 31-381).

\section{Recognition of symptoms}

Most participants, even those who described themselves as having no first symptoms, reported additional symptoms in response to the symptom checklist, suggesting that these symptoms were possibly ignored or not recognised as relevant, salient or indicative of serious illness (table 2).

\section{Effects of deprivation and rurality}

On univariate analysis, neither deprivation nor rurality was significantly associated with time to consultation. This was confirmed after adjustment for other significant variables in both models (tables 3 and 4). Of the related variables, increasing travel distance to general practices $(p=0.079)$ and social contact with GPs away from the surgery $(p=0.049)$, both of which are more common in rural areas, were associated with increasing time between first participant-defined symptom and consultation on univariate analysis, but not when adjusted for other factors (table 3). People who were currently or had previously been in paid employment consulted sooner after their earliest checklist symptom than those who had never been in paid employment $(p=0.037)$, but the difference was no longer statistically significant after adjusting for other variables $(\mathrm{p}=0.092$, table 4$)$.

A wide variety of factors were associated univariately with time to consultation. However, different factors were independently related to the time between first checklist symptom and presentation and the time between first participant-defined symptom and presentation (tables 3 and 4). 


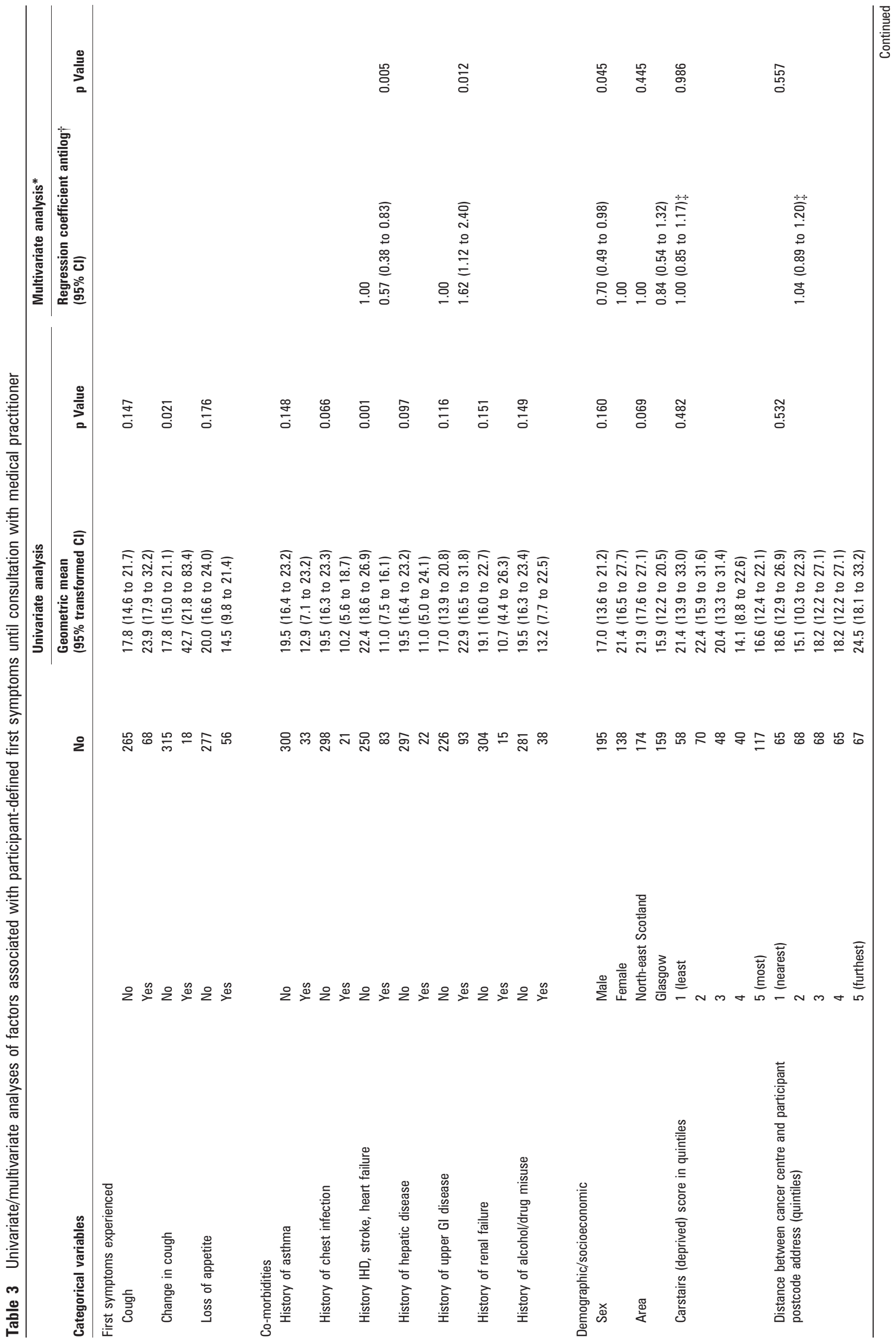




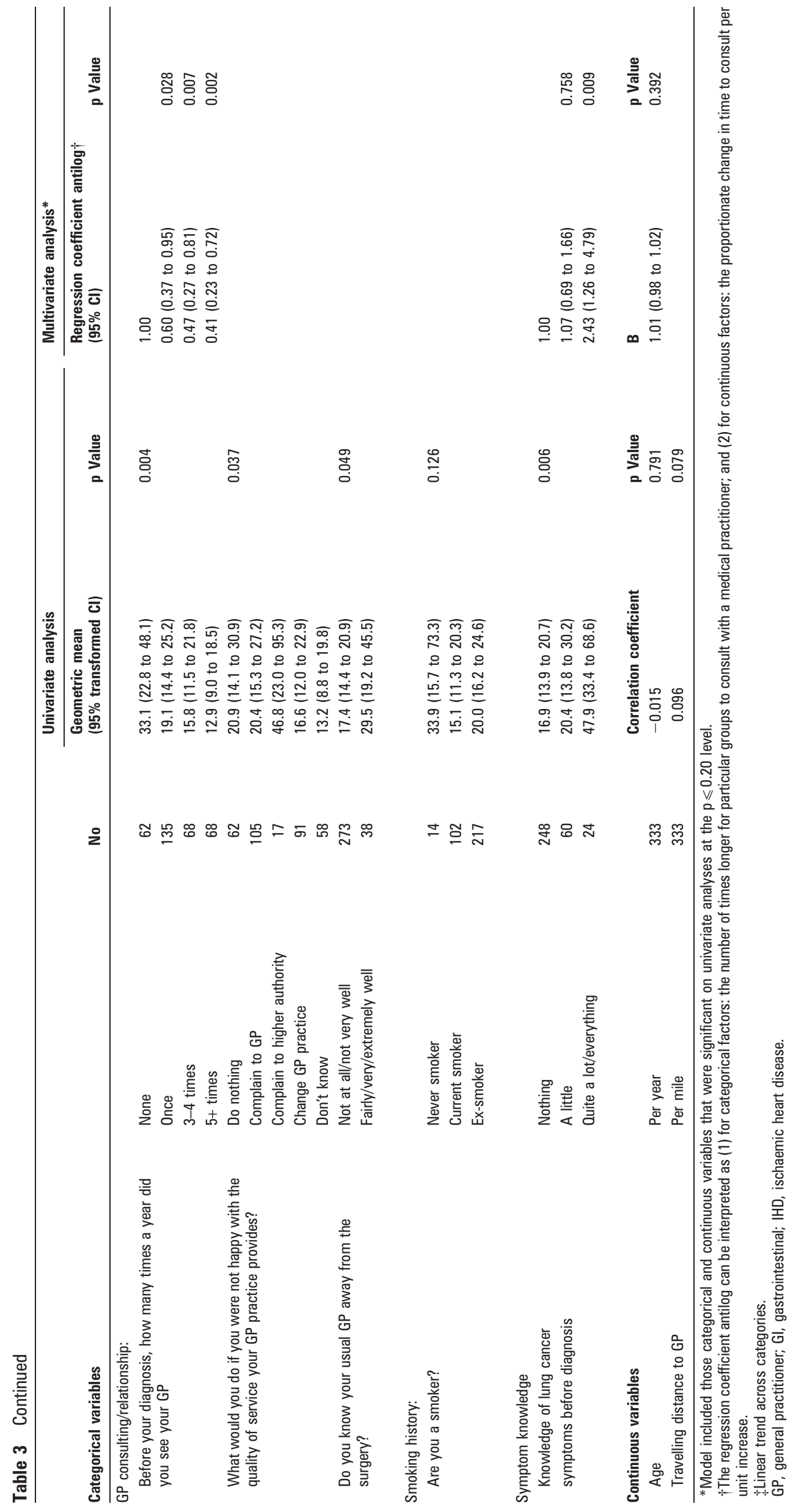

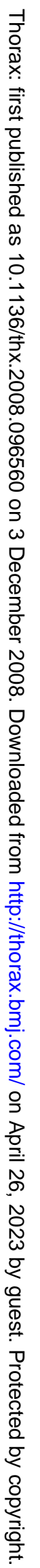




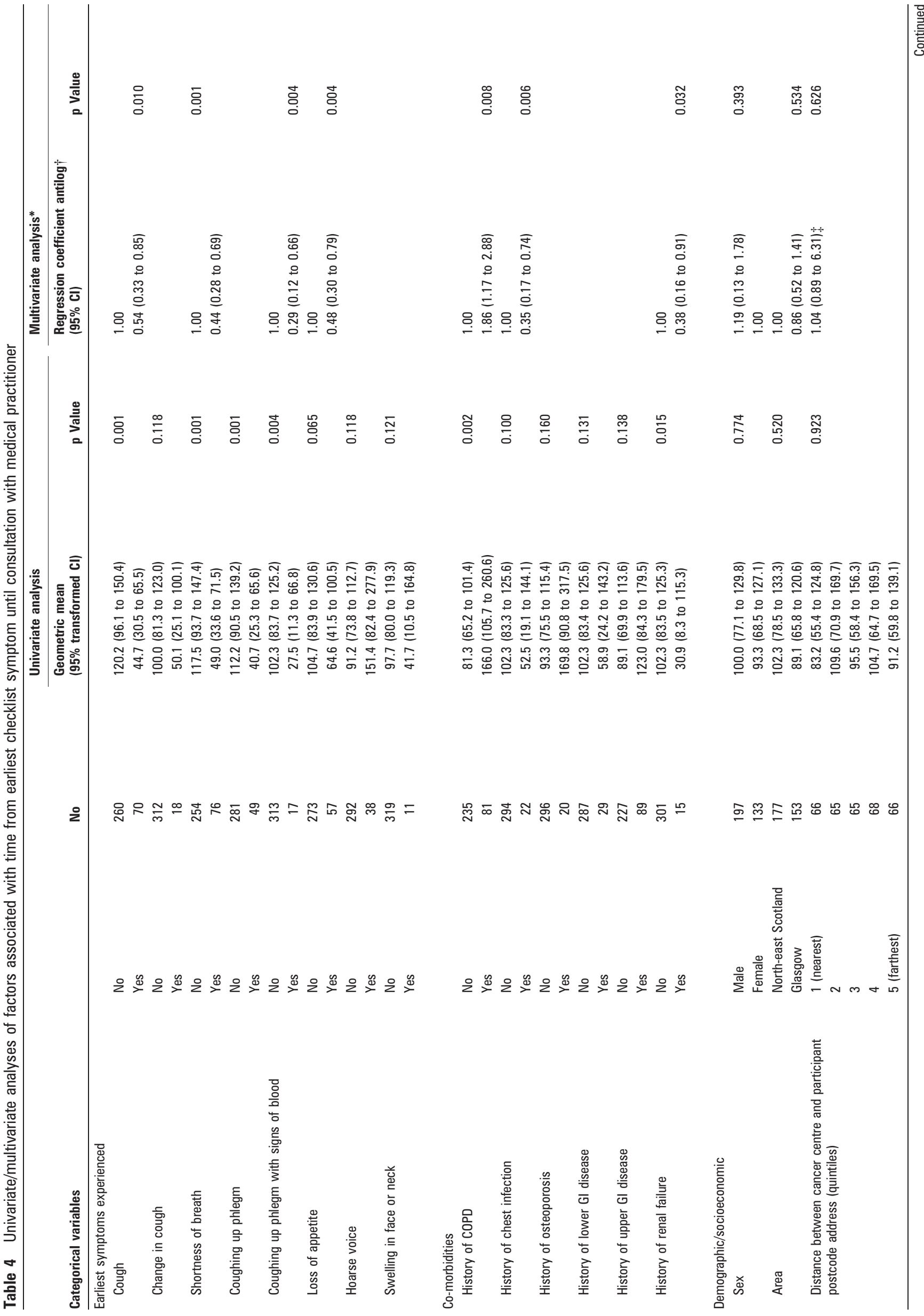




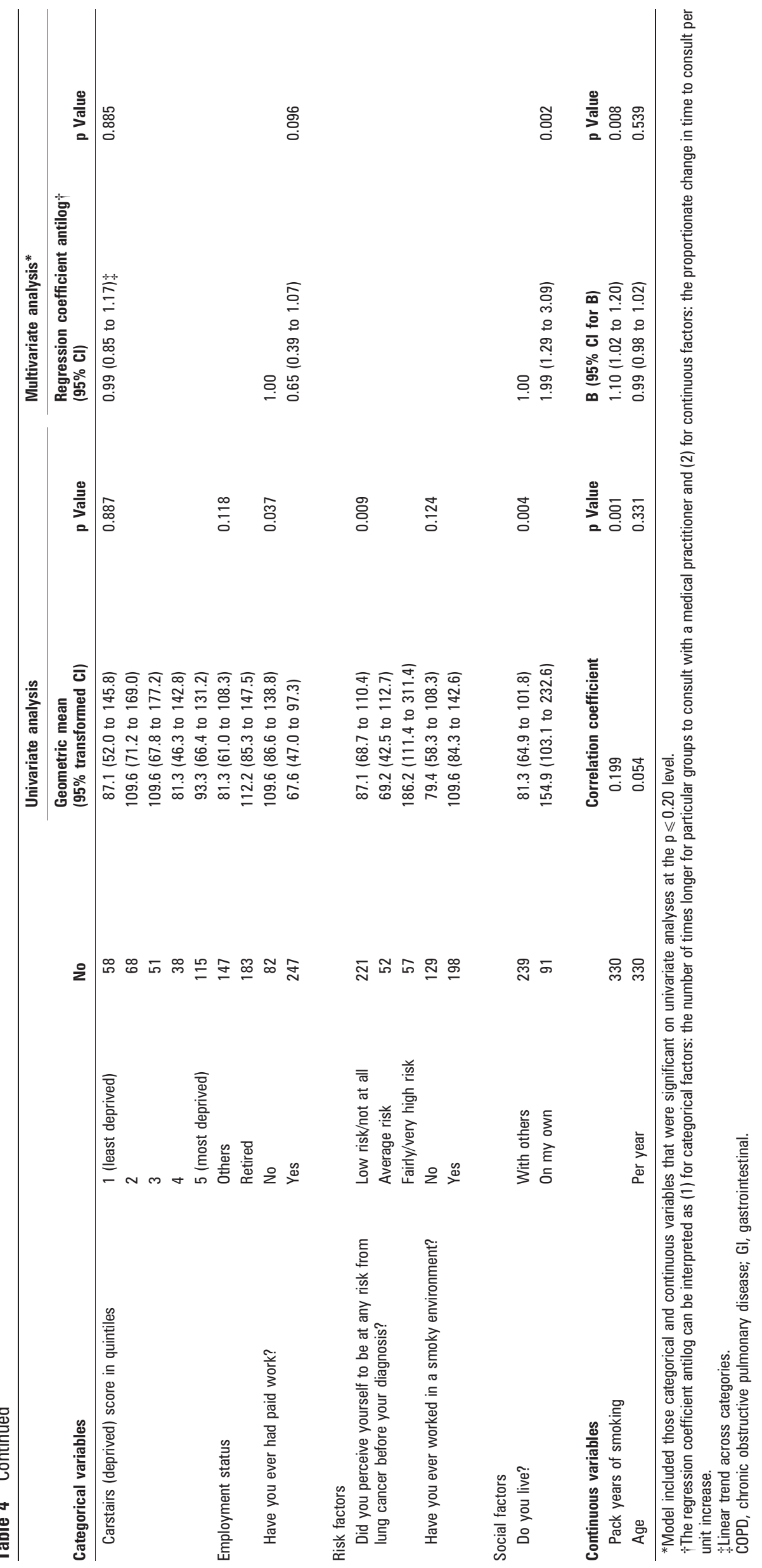


The shorter time between participant-defined first symptom and presentation to a medical practitioner showed little relationship with symptoms. On the other hand, it was predicted by previous illness, being shorter in those with cardiovascular disease but longer in those with previous upper gastrointestinal disease. People who regularly consulted their GP before their diagnosis consulted sooner with lung cancer symptoms, and those who stated they would complain to a higher authority if unhappy with their general practice took longer (although this was not an independent predictor)

For the longer time between earliest checklist symptom and presentation, more symptoms characteristics were significantly associated with time to consultation (table 4). Of social factors, living alone was the independent factor most strongly associated with time to consultation. Related variables (eg, having someone to talk to about symptoms or being prompted to consult by others) were not significant independent predictors. Some co-morbidities (previous chest infection or renal failure) were independently associated with a shorter time to consultation, while a history of chronic obstructive pulmonary disease (COPD) and increasing pack-years of smoking were independently associated with increased time to consultation.

\section{DISCUSSION}

We found no substantial differences in the time taken to present with symptoms of lung cancer between people living in rural, urban, affluent or deprived areas but, for all groups, these times were long. Most participants had unrecognised symptoms of lung cancer and half had experienced them for more than 14 weeks before presenting to a medical practitioner, indicating that symptoms were either ignored or not understood to be potentially serious even after the diagnosis of cancer had been made.

This study is the largest of its kind to collect such extensive data on reported lung cancer symptoms and symptom duration before consultation that we have been able to identify. ${ }^{28}$ This has allowed us to quantify the importance of symptoms, comorbidities and social factors as determinants of this lag time. A limitation is that it relied on self-reporting by participants so may have been subject to recall bias although, where we could check recall against case note records (for example, consultation dates), we found it to be reasonably good. We need to acknowledge that reports of some behaviours are not just affected by recall but by people's natural desire to avoid blaming themselves for waiting with serious symptoms or to avoid facing the stigma of a smoking-related disease. ${ }^{29}$ Also, first symptoms of lung cancer if non-specific can easily be dismissed. We were also aware that recruiting patients with lung cancer would be difficult because of their rapid clinical deterioration and high early death rate, so monitored all losses at the various stages of recruitment. This process confirmed that a notable proportion died early or were otherwise medically unfit to take part, and our data may not be representative of these groups.

Our findings add weight to qualitative research that shows symptoms are experienced for several months before consultation with a medical practitioner, ${ }^{8}$ even though it is generally thought to be asymptomatic until it is advanced. This contrasts with five previous quantitative studies which reported median times to consultation of 1 month or less. ${ }^{28}{ }^{30}$ In the National Survey of NHS patients, ${ }^{30}$ time before consultation was only reported for the minority of patients who presented directly to hospital either with incidental findings or as emergencies. This and the four smaller studies ${ }^{28}$ did not use symptoms checklists and their findings are in line with the shorter lag time we found from patient-defined first symptoms: our research shows that patients experience unrecognised symptoms for many preceding weeks. This study is also in agreement with other research reporting on the most common first clinical features of lung cancer. ${ }^{15}$

That smoking was associated with increased time to consultation might be viewed as counterintuitive, given that the relationship between smoking and lung cancer is so well known. On the other hand, we found that smokers said they did not perceive themselves to be at risk-this "unrealistic optimism" has been reported in other studies of risk perception, ${ }^{31} 32$ nor did we find any evidence that high perceived risk was associated with consulting sooner (if anything, we found the reverse). It could be that smokers were more tolerant of symptoms, regarding them as "normal" for smokers.

The most important social factor associated with time to consult in our study was living alone, which has been found previously in patients with breast cancer and heart disease. ${ }^{28} 3334$ This may be because co-habitees notice symptoms and "sanction help-seeking behaviour". Previous research has concentrated on the latter, ${ }^{11}$ but our findings suggest the former may be more important. We have confirmed the findings of recent qualitative research which suggested that co-morbidities may be important in causing patients to hold off before consulting, and quantified their importance. In particular, people with COPD took twice as long to consult with symptoms. More encouragingly, we also found that some comorbidities were associated with reduced time to consultation; those who had previously experienced a chest infection requiring hospital treatment consulted in half the time of others. This suggests that people who have previously been alerted to certain symptoms consult with them more quickly, providing encouragement that effective intervention may be possible.

The implications of our findings are twofold. First, lung cancer is almost always symptomatic, usually for several months before consultation. The median time from the earliest symptom to consultation is more than the estimated doubling time of lung cancer and plausibly long enough to affect stage at diagnosis and prognosis. $^{35}$ It follows that, if people with symptoms consulted earlier and were investigated appropriately, there is potential to improve survival from lung cancer. Second, most symptoms go unnoticed for several weeks, so earlier consultation will only occur if people are alert to symptoms and know to consult with them. Achieving this will not, however, be easy. Key processes include symptom recognition, motivation by people to have their symptoms investigated and stimulating triggers to consultation. A lung cancer awareness campaign may be of merit. However, it is not yet known if this can be achieved to an extent that could affect survival, so further research is needed. Further research is also needed to understand the particular issues relating to presentation in those who present in poor condition or who rapidly deteriorate.

Practitioners, in particular GPs, should be aware of the potential to diagnose lung cancer earlier. This includes recognising and acting on chest symptoms, particularly in high-risk groups, and being aware that patients may not have understood the potential significance of their new chest symptoms, especially if they have a history of COPD, live alone and have smoked for a long time. 
Acknowledgements: The authors thank all the patients who kindly gave their time to participate in the study and the following people for their help, advice and guidance throughout the study: the lung nurse specialists involved in recruitment (lona Brisbane, Louise Brown, Penny Downer, Shona Haggart, Lynne McGuiness and John McPhelim); Dr David Dunlop, Consultant Medical Oncologist; Dr Richard Jones, Consultant Clinical Oncologist; Dr Joe Legge, Consultant in Thoracic Medicine; Dr Nazia Mohammed, Consultant Clinical Oncologist; Dr Rob Milroy, Consultant in Respiratory Medicine; Dr Brian Neilly, Consultant Physician; and Dr Marianne Nicolson, Consultant Medical Oncologist.

Funding: This study was funded by Cancer Research UK. Their role was solely as a funding body.

\section{Competing interests: None.}

Ethics approval: This study was approved by the North of Scotland research ethics committee and North Glasgow University Hospitals NHS Trust research ethics committee.

\section{REFERENCES}

1. Scottish Intercollegiate Guidelines Network (SIGN). Management of lung cancer. Edinburgh: SIGN, 2005

2. Cancer Research UK. Cancer Help UK. CancerStats key facts on lung cancer and smoking (updated 2007). http://info.cancerresearchuk.org/cancerstats/types/lung/ \#survival

3. Scottish Government. Cancer in Scotland: sustaining change lupdated 21 June 2005). http://www.scotland.gov.uk/Publications/2004/05/19344/36943.

4. Scottish Executive Health Department. Cancer scenarios: an aid to planning cancer services in Scotland in the next decade. Edinburgh: The Scottish Executive, 2001

5. Cancer Research UK. Cancer Help UK. Lung cancer survival statistics (updated September 2007). http://info.cancerresearchuk.org/cancerstats/types/lung/survival.

6. Bowen EF, Rayner CF. Patient and GP led delays in the recognition of symptoms suggestive of lung cancer. Lung Cancer 2002;37:227-8.

7. Kesson E, Bucknall CE, McAlpine LG, et al. Lung cancer management and outcome in Glasgow, 1991-92. Br J Cancer 1998;78:1391-5.

8. Corner J, Hopkinson J, Roffe L. Experience of health changes and reasons for delay in seeking care: a UK study of the months prior to the diagnosis of lung cancer. Soc Sci Med 2006;62:1381-91.

9. Burgess CC, Hunter MS, Ramirez AJ. A qualitative study of delay among women reporting symptoms of breast cancer. Br J Gen Pract 2001;51:967-71.

10. Tromp DM, Brouha XDR, De Leeuw JRJ, et al. Psychological factors and patient delay in patients with head and neck cancer. Eur J Cancer 2004:40:1509-16.

11. Smith LK, Pope C, Botha J. Patients' help-seeking experiences and delay in cancer presentation: a qualitative synthesis. Lancet 2005;366:825-31.

12. Campbell SM, Roland MO. Why do people consult the doctor? Fam Pract 1996;13:75-83.

13. Andersen BL, Cacioppo JT. Delay in seeking a cancer diagnosis: delay stages and psychophysiological comparison processes. Br J Soc Psychol 1995;34:33-52.

14. Locker D. Symptoms and illness. The cognitive organisation of disorder. London: Tavistock, 1981.
15. Koyi H, Hillerdal G, Branden E. A prospective study of a total material of lung cance from a county in Sweden 1997-1999: gender, symptoms, type, stage, and smoking habits. Lung Cancer 2002;36:9-14.

16. Campbell NC, Elliott AM, Sharp L, et al. Rural factors and survival from cancer: analysis of Scottish cancer registrations. Br J Cancer 2000;82:1863-6.

17. McLaren G, Bain M. Deprivation and health in Scotland: insights from NHS data. Edinburgh: ISD Publications, 1998.

18. Campbell NC, Elliott AM, Sharp $L$, et al. Rural and urban differences in stage at diagnosis of colorectal and lung cancers. Br J Cancer 2001;84:910-4.

19. Pollock AM, Vickers N. Deprivation and emergency admissions for cancers of colorectum, lung, and breast in south east England: ecological study. BMJ 1998;317:245-52.

20. Campbell NC, Elliott AM, Sharp L, et al. Impact of deprivation and rural residence on treatment of colorectal and lung cancer. Br J Cancer 2002;87:585-90.

21. Macleod U, Ross S, Twelves C, et al. Primary and secondary care management of women with early breast cancer from affluent and deprived areas: a retrospective review of hospital and general practice records. BMJ 2000;320:1142-5.

22. Robertson R, Campbell NC, Smith $S$, et al. Factors influencing time from presentation to treatment of colorectal and breast cancer in urban and rural areas. Br J Cancer 2004;90:1479-85.

23. Bain NSC, Campbell NC. Treating patients with colorectal cancer in rural and urban areas: a qualitative study of the patients' perspective. Fam Pract 2000;17:475-9.

24. Christensen ED, Harvald T, Jendresen M, et al. The impact of delayed diagnosis of lung cancer on the stage at the time of operation. Eur J Cardiothorac Surg 1997:12:880-4.

25. Bozcuk H, Martin C. Does treatment delay affect survival in non-small cell lung cancer? A retrospective analysis from a single UK centre. Lung Cancer 2001;34:243-52.

26. ISD Scotland. Information and statistics. www.isdscotland.org/isd/3211.html.

27. CRUK Cancer Research UK. Cancer Help UK. Information service about cancer and cancer care. www.cancerhelp.org.uk/help/default.asp?page $=2964$.

28. Macdonald S, Macleod U, Mitchell E, et al. Factors influencing patient and primary care delay in the diagnosis of cancer: a database of existing research and its implications for future practice. Final Report to the Department of Health (Ref 1217522). Glasgow: University of Glasgow, 2004.

29. Chapple A, Ziebland S, McPherson A. Stigma, shame and blame experienced by patients with lung cancer: qualitative study. BMJ 2004;328:1470-3.

30. Allgar VL, Neal RD. Delays in the diagnosis of six cancers: analysis of data from the National Survey of NHS patients: Cancer. Br J Cancer 2005;92:1959-70.

31. Weinstein ND, Marcus SE, Moser RP. Smokers' unrealistic optimism about their risk. Tob Control 2005;14:55-9.

32. Arnett $\mathbf{J}$, Optimistic bias in adolescent and adult smokers and nonsmokers. Addictive Behaviors 2000;25:625-32.

33. Burgess CC, Ramirez AJ, Richards MA, et al. Who and what influences delayed presentation in breast cancer? Br J Cancer 1998;77:1343-8.

34. Horne R, James D, Petrie K, et al. Patients' interpretation of symptoms as a cause of delay in reaching hospital during myocardial infarction. Heart 2000;83:388-93.

35. Thunnissen FBJM, Schuurbiers OCJ, den Bakker MA. A critical appraisal of prognostic and predictive factors for common lung cancers. Histopathology 2006:48:779-86.

\section{BMJ Careers online re-launches}

BMJ Careers online has re-launched to give you an even better online experience. You'll still find our online services such as jobs, courses and careers advice, but now they're even easier to navigate and quicker to find.

New features include:

- Job alerts - you tell us how often you want to hear from us with either daily or weekly alerts

- Refined keyword searching making it easier to find exactly what you want

- Contextual display - when you search for articles or courses we'll automatically display job adverts relevant to your search

- Recruiter logos linked directly to their organisation homepage - find out more about the company before you apply

- RSS feeds now even easier to set up

Visit careers.bmj.com to find out more. 